\title{
Inhaler device handling: have we really started to address the problem?
}

\author{
Sinthia Z. Bosnic-Anticevich
}

Affiliation: Woolcock Institute, University of Sydney and Sydney Local Health District, Sydney, Australia.

Correspondence: Sinthia Z. Bosnic-Anticevich, Woolcock Institute, University of Sydney, 431 Glebe Point Road, Glebe, NSW, 2037, Australia. E-mail: sinthia.bosnic-anticevichlasydney.edu.au

@ERSpublications

Let's consider again: how big a problem is inhaler technique and how important is it? http://ow.ly/rwfu308ircJ

Cite this article as: Bosnic-Anticevich SZ. Inhaler device handling: have we really started to address the problem? Eur Respir J 2017; 49: 1700120 [https://doi.org/10.1183/13993003.00120-2017].

How big a problem is inhaler technique and how important is it? In this issue of the European Respiratory Journal we are presented with a "real-life" study exploring the inhaler technique of almost 3000 patients with chronic obstructive pulmonary disease (COPD) and the relationship between inhaler device handling and disease control. This observational, cross-sectional study, conducted by Molimard et al. [1], assesses the handling of devices by patients visiting general practitioners and pulmonologists and in so doing determines two key findings. 1) Over 50\% of patients with COPD are not able to use their devices correctly. 2) Patients making "critical errors" in their device handling are two-times more likely to experience severe COPD exacerbations than those not making critical errors $(3.3 \%$ versus $6.9 \%$ in the previous 3 months, respectively, OR 1.86).

Molimard et al. [1] are the first to focus on inhaler technique and COPD outcomes and their study joins a handful of papers all of which confirm that poor inhaler technique is associated with poor asthma disease outcomes [2-7]. In fact, the relationship between inhaler technique and disease outcomes is further supported by complementary evidence, which shows that by improving inhaler technique improvements in disease outcome can be achieved [8-11]. For me, the current research of Molimard et al. [1] is a disappointing reminder that inhaler technique remains a big problem and a reaffirmation that it really does matter.

What are your thoughts when you read this? Are you surprised? Are you troubled? Do you begin to reflect on whether this relates to your patients or those of other physicians, nurses, or pharmacists? Do you make a mental note of it and vow to check the inhaler technique for all your patients from now on? Or do you read it, acknowledge it and move on to the next manuscript? Unfortunately, data suggests that you will probably "read on". In a recent review, SANCHIS et al. [12] explored the errors in inhaler technique made by patients over the last 40 years. Based on this review the authors note that inhaler technique has been a problem since the launch of the pressurised metered-dose inhaler (pMDI) in the 1960's and that, 40 years later, almost nothing has changed. That is, looking back over 40 years-worth of research and practice we can see that the proportion of patients able to demonstrate correct inhaler technique remains unacceptably low despite the plethora of research in this area (figure 1). Therefore, the real question is, despite knowing that poor inhaler technique is a big problem and that it really does matter, why have we not yet solved this problem?

In a review by PRICE et al. [13], a comprehensive range of reasons for poor inhaler technique are noted, ranging from the device, the patient, the healthcare provider, the technology used, and/or the policies in place. In a practical sense, the possible causes for this problem are many and varied. Therefore, perhaps we need to ask ourselves, is the problem too difficult to solve and are we unrealistic in believing that it can be

Received: Jan 182017 | Accepted: Jan 182017

Conflict of interest: None declared.

Copyright @ERS 2017 


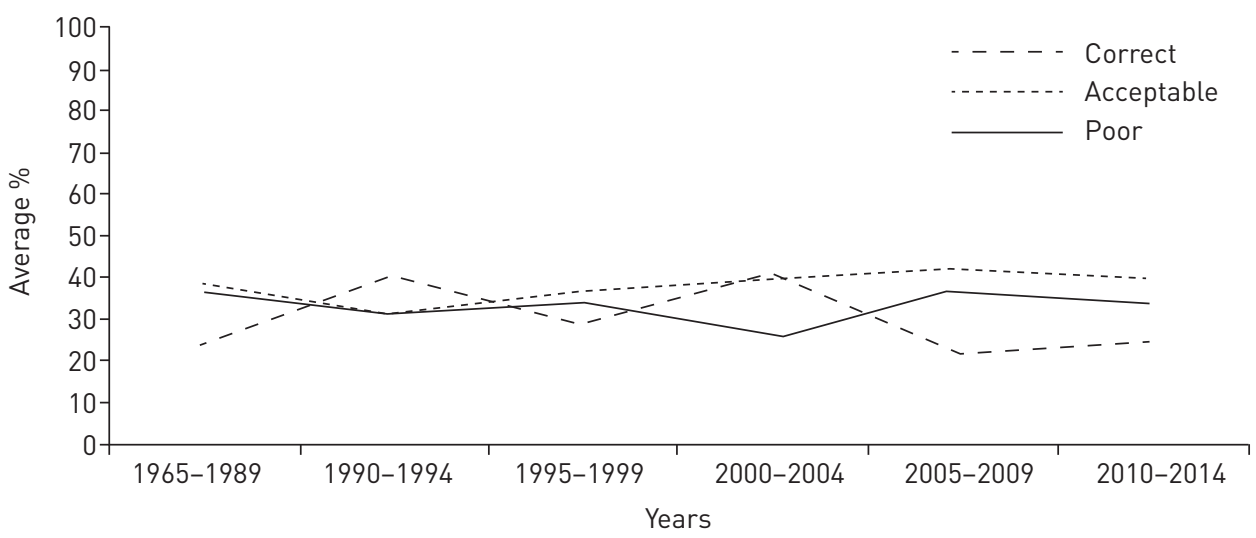

FIGURE 1 Average of correct, acceptable, and poor tests over the 40 years of observation reviewed by Sanchis et al. As not all studies included this information, data were available for 94 groups. Inhaler technique was assessed by the authors of the included articles and considered "correct" by Sanchis et al. when all steps were performed in agreement with a list of essential inhalation manoeuvers. Technique was considered "acceptable" when approximately $80 \%$ of these steps were correct and no critical error was observed and "poor" when the researchers observed one or more critical errors and/or there were errors in more than $50 \%$ of the inhalation procedure steps. The general impression is one of a stable distribution of averages because there are no major, significant changes in any of the three categories. Reproduced and modified from [12] with permission.

fixed with the current devices? Do we lack awareness or knowledge on how to do it? Do we lack the right tools/support to help our patients? Are patients just not playing their role? Have we given up? Or have we perhaps not even started? Let's refer back to the evidence in considering these questions.

Firstly, there is an abundance of research suggesting that the problem of poor inhaler technique is not "too difficult" to solve. That is, research indicates that regardless of the device, almost all patients can be taught how to use an inhaler correctly. Yes it requires an individualised approach [14], time and effort, often repeated instruction [8, 15-17], appropriate device selection [18-20] and effective educational techniques $[8,16,21,22]$ but, when it comes to being able to solve the problem, it absolutely can be done.

So, the next question is, do healthcare providers lack awareness, knowledge, or motivation to solve the problem? It is reasonable to say that, when it comes to awareness and tools, we are not lacking. In fact, the Global Initiative for Asthma (GINA) report (2016) [23] and the Global Initiative for Chronic Obstructive Lung Disease (GOLD) report (2017) [24] collectively mention inhaler technique over 70 times. Furthermore, when it comes to tools, there are an abundance of local and international organisations/ manufacturers providing websites, resources and educational tools to help us train our patients on how to use their inhalers correctly [25]. Therefore, while lack of awareness and availability of tools are not the problem, healthcare provider knowledge and/or skills most certainly are. Despite the challenges associated with working with patients with chronic illness, there is convincing evidence that many healthcare providers lack the basic knowledge and/or technical skills to teach inhaler technique and seldom receive formal training in how to do so [26-31]. We don't know why this is the case but we do have to consider healthcare providers motivations and whether they have the ability to engage the patient around inhaler technique. Let's face it: inhaler technique is often considered a possibly important but mostly boring aspect of respiratory disease management.

But what if we are able to demonstrate that inhaler technique is more than just a physical skill and that there is more to it than just learning how? I believe we have some evidence to suggest exactly this. That is, I believe there is some limited evidence suggesting that inhaler technique is caught up within a complex framework of disease management issues, which fuses patient attitudes and beliefs and is exemplified within patient self-management behaviours, including both poor inhaler use and poor adherence. Evidence supporting this opinion is as follows.

It is well documented that poor inhaler technique and poor adherence co-exist [32-36]. Further to this, it has been suggested that this co-existence may be related or that the issues should at least be considered together [37, 38]. Exploring inhaler use in people with asthma, Ovchinikova et al. [17] identified that inhaler technique was related to patient psychosocial factors such as motivation. Further exploration of motivation indicated that patients' perceptions of the threat posed by their asthma, their perceived confidence in the strategies suggested for managing their asthma, and their confidence in carrying out those strategies were linked to their ability to retain correct inhaler technique over time [39]. 
Complementary to these findings, JAHEDi et al. [40] identified that inhaler technique is unrelated to perceptions of, or satisfaction with, inhaler devices but rather perceptions of the patient's asthma and its management. Therefore, in light of these preliminary findings, I think we must question our current approach to inhaler technique.

Don't get me wrong, I believe that there is certainly value in the suggestions by Molimard et al. that we must keep training our patients and that better devices need to be developed (despite the lack of evidence that new devices impact on long term clinical outcomes [41]). However, I believe that the heart of the inhaler technique problem lies within the attitudes and perceptions of the patient and probably the healthcare providers. Unless we start to explore this hypothesis and reconceptualise the role of inhaler technique in disease management, we might still have the same problem in the years to come.

\section{References}

1 Molimard M, Raherison C, Lignot S, et al. Chronic obstructive pulmonary disease exacerbation and inhaler device handling: real-life assessment of 2935 patients. Eur Respir J 2017; 49: 1601794.

2 Melani AS, Bonavia M, Cilenti V, et al. Inhaler mishandling remains common in real life and is associated with reduced disease control. Respir Med 2011; 105: 930-938.

3 Giraud V, Roche N. Misuse of corticosteroid metered-dose inhaler is associated with decreased asthma stability. Eur Respir J 2002; 19: 246-251.

4 Molimard M, Raherison C, Lignot S, et al. Assessment of handling of inhaler devices in real life: an observationa study in 3811 patients in primary care. J Aerosol Med 2003; 16: 249-254.

5 Lavorini F, Magnan A, Dubus JC, et al. Effect of incorrect use of dry powder inhalers on management of patients with asthma and COPD. Respir Med 2008; 102: 593-604.

6 Al-Jahdali H, Ahmed A, Al-Harbi A, et al. Improper inhaler technique is associated with poor asthma control and frequent emergency department visits. Allerg Asthma Clin Immunol 2013; 9: 8.

7 Bonini M, Usmani OS. The importance of inhaler devices in the treatment of COPD. COPD Res Pract 2015; 1: 9

8 Basheti IA, Reddel HK, Armour CL, et al. Improved asthma outcomes with a simple inhaler technique intervention by community pharmacists. J Allergy Clin Immunol 2007; 119: 1537-1538.

9 Giraud V, Allaert F, Roche N. Inhaler technique and asthma: feasibility and acceptability of training by pharmacists. Respir Med 2011; 105: 1815-1822.

10 Goris S, Tasci S, Elmali F. The effects of training on inhaler technique and quality of life in patients with COPD. J Aerosol Med Pulm Drug Deliv 2013; 26: 336-344.

11 Harnett C, Hunt EB, Bowen B, et al. A study to assess inhaler technique and its potential impact on asthma control in patients attending an asthma clinic. J Asthma 2014; 51: 440-445.

12 Sanchis J, Gich I, Pedersen S, Systematic review of errors in inhaler use: has patient technique improved over time? Chest 2016; 150: 394-406.

13 Price D, Bosnic-Anticevich S, Briggs A, et al. Inhaler competence in asthma: common errors, barriers to use and recommended solutions. Respir Med 2013; 107: 37-46.

14 Papi A, Haughney J, Virchow JC, et al. Inhaler devices for asthma: a call for action in a neglected field. Eur Respir J 2011; 37: 982-985.

15 Basheti IA, Armour CL, Bosnic-Anticevich SZ, et al. Evaluation of a novel educational strategy, including inhaler-based reminder labels, to improve asthma inhaler technique. Patient Educ Couns 2008; 72: 26-33.

16 Bosnic-Anticevich SZ, Sinha H, So S, et al. Metered-dose inhaler technique: the effect of two educational interventions delivered in community pharmacy over time. J Asthma 2010; 47: 251-256.

17 Ovchinikova L, Smith L, Bosnic-Anticevich S. Inhaler technique maintenance: gaining an understanding from the patient's perspective. J Asthma 2011; 48: 616-624.

18 Haughney J, Price D, Barnes NC, et al. Choosing inhaler devices for people with asthma: current knowledge and outstanding research needs. Prim Med CME 2010; 3: 125-131.

19 Chrystyn H, Price D. Not all asthma inhalers are the same: factors to consider when prescribing an inhaler. Prim Care Respir J 2009; 18: 243-249.

20 Scichilone N. Asthma control: the right inhaler for the right patient. Adv Ther 2015; 32: 285-292.

21 Toumas-Shehata M, Price D, Basheti IA, et al. Exploring the role of quantitative feedback in inhaler technique education: a cluster-randomised, two-arm, parallel-group, repeated-measures study. NPJ Prim Care Respir Med 2014; 24: 14071.

22 King $\mathrm{T}$, Kho E, Tiong $\mathrm{Y}$, et al. Comparison of effectiveness and time-efficiency between multimedia and conventional counselling on metered-dose inhaler technique education. Singapore Med J 2015; 56: 103-108.

23 Global Initiative for Asthma. Global Strategy for Asthma Management and Prevention, 2016. www.ginasthma.org Date last accessed: January 2017. Date last updated: 2016.

24 Global Initiative for Chronic Obstructive Lung Disease (GOLD). Global Strategy for the Diagnosis, Management and Prevention of COPD, 2017. http://goldcopd.org Date last accessed: January 2017. Date last updated: 2017.

25 Lavorini F, Levy M, Corrigan C, et al. The ADMIT series-issues in inhalation therapy. 6) Training tools for inhalation devices. Prim Care Respir J 2010; 19: 335-341.

26 Chopra N, Oprescu N, Fask A, et al. Does introduction of new "easy to use" inhalational devices improve medical personnel's knowledge of their proper use? Ann Allergy Asthma Immunol 2002; 88: 395-400.

27 Basheti IA, Armour CL, Reddel HK, et al. Long-term maintenance of pharmacists' inhaler technique demonstration skills. Am J Pharm Educ 2009; 73: 32.

28 Hanania NA, Wittman R, Kesten S, et al. Medical personnel's knowledge of and ability to use inhaling devices. Metered-dose inhalers, spacing chambers, and breath-actuated dry powder inhalers. Chest 1994; 105: 111-116.

29 Basheti IA, Bosnic-Anticevich SZ, Armour CL, et al. Checklists for powder inhaler technique: a review and recommendations. Respir Care 2014; 59: 1140-1154.

30 Nguyen Y, Wainwright C, Basheti I, et al. Do health professionals on respiratory wards know how to use inhalers? J Pharm Pract Res 2010; 40: 211-216. 
31 Alismail A, Song C, Terry M, et al. Diverse inhaler devices: a big challenge for health-care professionals. Respir Care 2016; 61: 593-599.

32 Reddel HK, Sawyer SM, Everett PW, et al. Asthma control in Australia: a cross-sectional web-based survey in a nationally representative population. Med J Aust 2015; 202: 492-497.

33 Nathan R, Thompson P, Price D, et al. Taking aim at asthma around the world: global results of the Asthma Insight and Management Survey in the Asia-Pacific region, Latin America, Europe, Canada, and the United States. J Allergy Clin Immunol Pract 2015; 3: 734-742.

34 Price D, Fletcher M, van der Molen T. Asthma control and management in 8000 European patients: the recognise asthma and link to symptoms and experience (REALISE) survey. NPJ Prim Care Respir Med 2014; 24: 14009.

35 Armour CL, Lemay K, Saini B, et al. Using the community pharmacy to identify patients at risk of poor asthma control and factors which contribute to this poor control. J Asthma 2011; 48: 914-922.

36 Sriram K, Percival M. Suboptimal inhaler medication adherence and incorrect technique are common among chronic obstructive pulmonary disease patients. Chron Respir Dis 2016; 13: 13-22.

37 Braido F, Chrystyn H, Baiardini I, et al. "Trying, but failing" - the role of inhaler technique and mode of delivery in respiratory medication adherence. J Allergy Clin Immunol Pract 2016; 4: 823-832.

38 Newman S. Improving inhaler technique, adherence to therapy and the precision of dosing: major challenges for pulmonary drug delivery. Expert Opin Drug Deliv 2014; 11: 365-378.

39 Ovchinikova L. "Knowing how" is not enough: a mixed methods exploration of inhaler technique maintenance in patients with asthma. Sydney, University of Sydney, 2014.

40 Jahedi L, Downie S, Saini B, et al. Inhaler technique in asthma: how does it relate to patients' preferences and attitudes toward their inhalers? J Aerosol Med Pulm Drug Deliv 2016; 29: 1-11.

41 Ninane V, Vandevoorde J, Cataldo D, et al. New development in inhaler devices within pharmaceutical companies: a systematic review of the impact on clinical outcomes and patient preferences. Respir Med 2015; 109: $1430-1438$ 